\title{
Mathematical modelling of dominant features identification for tool wear monitoring in hard turning by using Acoustic emission
}

\author{
D. Kondala Rao ${ }^{a}$, Kolla Srinivas ${ }^{b}$, Md. Hasheer SK ${ }^{c}$, and K. Hari Prasad ${ }^{d}$ \\ ${ }^{\text {a,b,c,d }}$ Faculty of Mechanical Engineering, R.V.R. J.C. College of Engineering, Guntur, Andhra Pradesh, India
}

Article History: Received: 11 January 2021; Accepted: 27 February 2021; Published online: 5 April 2021

\begin{abstract}
In machining processes generally tool wear will be obtained with varying proportions. In the present work, the number of dominant features, which affect the tool wear, are studied and computed on Inconel 718 as work material with varying hardness $(51,53 \& 55 \mathrm{HRC})$ levels. The condition monitoring was done on three tools namely uncoated carbide, coated carbide and ceramic tools. By using L9 Taguchi's orthogonal array, speed, feed, depth of cut (DOC) and hardness are considered as input operating parameters. By indirect method of Acoustic emission (AE) technique, signals were collected using Lab VIEW software and dominating features were calculated using the MATLAB. The features were trained in neural network and got the relation between tool wear, surface roughness, temperature and features. The simulated data was analyzed by Grey relational analysis (GRA) and the dominating features ranking sequence was obtained for all the three tools and same ranking was also observed with ANOVA. Since there are no common influencing features among these three tools and hence further investigation continued with statistical mathematical modeling. With Akaike information criterion a mathematical model is developed to find the dominant features. By mathematical modeling the sequence in evaluating tool wear was found to be Kurtosis, Frequency, Variance, Mean and RMS and also a relation between tool wear and dominant features was developed which can be readily used by layman for calculating the tool wear.
\end{abstract}

Keywords: Hard turning, Tool wear Monitoring, Dominant features, AE, GRA, Akaike

\section{Introduction}

Hard turning has emerged as a recent new technology that can be used for products with a hardness value of $45 \mathrm{HRC}$ or greater in finishing operations. With the advancement of various super hard cutting tool materials along with correct machine tools, the turning of hardened steel to around $45 \mathrm{HRC}$ is called soft machining. Turning of more than $45 \mathrm{HRC}$ of hardened steel is known as fast machining and examples of hardened steels which are commonly used in engineering applications like dies and molds, automotive and machine tool parts. There are number of ways by which tool wear develops in machining processes. Damaged tools definitely affect the finishing of surface and hence it is necessary to establish tool wear monitoring (TWM) systems by means of which the operator takes corrective steps to improve the quality of products. TWM systems are also termed as tool condition monitoring (TCM) systems. Number of articles have reviewed the enhancements to be made in TCM systems.

Apart from reducing downtime, by avoiding unnecessary tool changes, products cost also reduced extensively by using effective TWM. By proper TCM the product quality improves. It eliminates tool deflection \& chatter. For the last 35 years (LI Dan, 1990;Garikapati, 2020) much research has been taken place in TCM. Due to complex nature of machining processes, even though many advanced methods have been put forward, only few were successful. Based on the classification of sensors, the successful methods used were direct techniques which uses radioactive electrical resistance \& optical concepts etc. Whereas indirect methods use Acoustic emission (AE), Vibration, Cutting force, Spindle motor current concepts etc. Recent studies have focused on how best indirect monitoring methods could improve the quality of processes. The most efficient indirect method which was emerged in recent times was $\mathrm{AE}$

In traditional machining, tool wear can be tracked using various indirect variables sensitive to the wear of the equipment. The widely used indirect parameters are the three cutting force components as stated by (Teti, 2010). (Moriwaki, 1990; Shankar, 2020; Vasanth, 2017) operated within the $100 \mathrm{kHz}$ and $1 \mathrm{MHz}$ frequency ranges. Therefore, the correct frequency range of AE signal was experimentally tested to track the wear of the instruments. (Blum, 1990) observed the relationship between the AE waves and the cutting phase with in the frequency range between $100 \mathrm{kHz}$ to $300 \mathrm{kHz}$. (Narayanan, 1994; Vasanth 2018) prepared a method for the coated tool life estimation based on AE measurements and analysis. (Ravindra 1997;Battula, 2020) and (Byrne, 1995) investigated the acoustic emission in metal cutting for tool quality monitoring. The carbide tool coated with multilayers was used to machine C60 steel and tool wear was tracked by the AE signals detection and analysis. The prospect of using AE methods as a wear tracking technique for online applications has been examined. A research by (Dalpiaz, 1988; Latchoumi, 2016) found that there was no definite pattern with tool wear in the AE parameters, but rather a general random activity with unexpected variations in the phase of deterioration phenomena. Through their pattern study, (Emel, 1995) have identified $100 \mathrm{kHz}$ to $1 \mathrm{MHz}$ was the most accurate frequency range through their pattern study. 
Catastrophic device failure was detected by (Jemielnaik, 1998) by the development of statistical signal processing algorithm to classify kurtosis signal from acoustic emission, skew and RMS. They concluded that when compared with RMS, kurtosis and skew were better markers of catastrophic instrument failure. To know when the failure has occurred, reference signals are obtained at the same time by measurement of cutting force. Using acoustic emission signals along with vibrations \& cutting forces, models were developed by (Sharma, 2006) to estimate tool wear. The predicted tool and actual tool wear values were found and established a close relationship between them. Roll bearing deterioration was tracked by (Eftekharnejad, 2011) by using vibration \& $\mathrm{AE}$ techniques and the results were compared. Because of wide range of frequency when used AE signal for tool condition monitoring it was thought to be superior when compared with that of vibration technique and ambient noise. It also does not interfere with the process.

\section{Dominant Feature}

A significant number of features are measured in many industrial applications. However, it has been found, that the inclusion of additional features above a certain threshold contributes to a worse result. In addition, the prime features influence other aspects of the recognition process, such as learning time, precision and the sample size which is most important. Moreover, measuring additional features contributes to the process of identification of increase in complexity, computing space and time.

In this work an attempt is made to define the dominant characteristics for tool wear by using acoustic emission technique. In industrial turning machines, tool wear prediction time series could be obtained by selecting dominant features. GRA is used as a software resolution method to select features. This is achieved by an online, indirect real time approach with AE sensors installed. The suggested method is tested on an automated high-speed turning machine using a single point cutting tool. The baseline time plot of real wear versus time of the device is taken. Eleven features were calculated from the measured AE data, commonly used for machinery monitoring in industry. The GRA method is then used with the aid of Artificial Neural Network (ANN) to pick the dominant function.

A high-speed milling machine ball nose cutter tool wear was estimated by identification of dominant features with measurement of AE signals by (Zhou, 2006). The results showed that with dominant features, the tool wear was predicted more effectively. A relationship between kurtosis, skew and tool wear was proposed by (KannateyAsibu, 1982). Fisher's linear discriminate analysis was used by (Zhu, 2010) to select cutting force features for tool wear monitoring. Correlation-based feature selection technique was adopted by (Binsaeid, 2010) to estimate the influence of the features from multiple sensor signals.

\section{Methodology}

The proposed method is tested using a single point cutting tool in an industrial high-speed turning lathe machine Lokesh TL250. Acoustic emission measurements are noted over a period using AE sensor. During the measuring period, the tool is periodically removed from the chuck, and tool wear is measured using Tool Makers microscope. Eleven features, generally used for machinery monitoring in industries, are calculated from the measured data. The optimal feature values were observed using the grey relational analysis along with ANN. Among the eleven features obtained, the most contributing features were identified by applying ANOVA.

\subsection{Machining Parameters and their Levels}

Taguchi L9 orthogonal array is used to carryout the number of experimental runs and the variations of each run. The turning experiments are performed on LOKESH TL250 Computer numerical control (CNC) lathe. The cutting parameter values along with their levels are presented in Table 1.

Table 1 Parameter values and levels during experimentation.

\begin{tabular}{|c|c|c|c|c|}
\hline \multirow{2}{*}{ Level } & \multicolumn{4}{|c|}{ Operating parameters } \\
\cline { 2 - 5 } & $\begin{array}{l}\text { Speed } \\
(\mathrm{m} / \mathrm{min})\end{array}$ & $\begin{array}{l}\text { Feed } \\
(\mathrm{mm} / \mathrm{rev})\end{array}$ & $\begin{array}{l}\text { Depth of cut } \\
(\mathrm{mm})\end{array}$ & $\begin{array}{c}\text { Hardness } \\
(\text { HRC })\end{array}$ \\
\hline 1 & 50 & 0.050 & 0.15 & 51 \\
\hline 2 & 65 & 0.075 & 0.20 & 53 \\
\hline 3 & 80 & 0.100 & 0.25 & 55 \\
\hline
\end{tabular}




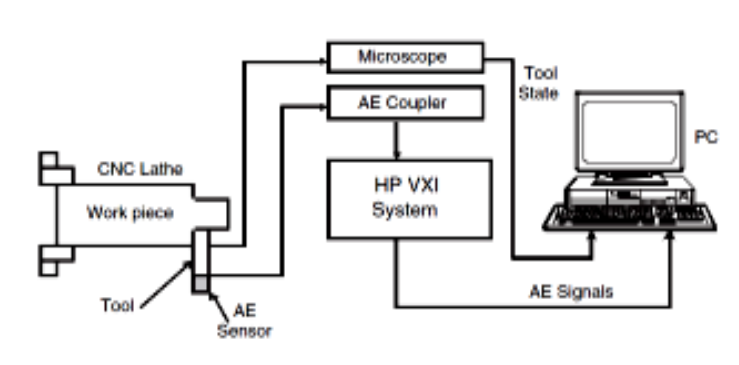

Figure 1 Experimental set-up scheme

\section{Experimental Setup}

The schematic of the experimental setup developed in this work is depicted in the Figure 1. A Lokesh Machines Limited, 20kW, CNC lathe was used for machining. Inconel 718 Nickel based alloy of of hardness 51,53 and 55HRC was used as the work material. TNMG160408MS SW05 uncoated carbide cutting tool insert, TNMG160408MU PR1305 (PVD) mega coated carbide cutting tool insert, TNMG160408 A65 ceramic tool insert and MTJNL 2020K16 Tool holder were used. Acoustic emission sensor with a frequency range of $50 \mathrm{kHZ}-400$ $\mathrm{kHZ}$ was used to capture the signals due to flank wear.

\subsection{Measurement and processing of AE signals during cutting}

The AE signals have been recorded at various stages of cutting until failure of the tool. The AE signals were measured using a Kistler $8152 \mathrm{C} \mathrm{AE} \mathrm{piezoelectric} \mathrm{sensor} \mathrm{which} \mathrm{has} \mathrm{been} \mathrm{mounted} \mathrm{on} \mathrm{top} \mathrm{of} \mathrm{the} \mathrm{tool} \mathrm{holder} \mathrm{with}$ magnetic clamp (Kistler 8443B), and placed possibly near to the tool-insert. The AE sensor has a frequency range from $50 \mathrm{kHz}$ to $400 \mathrm{kHz} 1 \mathrm{~Hz}$ to $10 \mathrm{kHz}$ and sensitivity of the sensor is $57 \mathrm{dBref} 1 \mathrm{~V} /(\mathrm{m} / \mathrm{s})$. A KISTLER 5125C type coupler is used to pass the signal through. The sensor captures the AE signals in the z-direction. The trained signal is finally sent to system with LabVIEW based software for display and storage.

\section{Results and Discussion}

Experiments were conducted and using AE signals data, the analysis was carried out and the results are obtained. The flank wear of tool is determined using Tool maker's microscope, the surface roughness of the work pieces was measured by using Taly surf and temperature was measured by Infrared thermometer were given in the table $2,3 \& 4$. In this work, for every $120 \mathrm{~mm}$ length of cut the tool flank wear was measured for each work piece.

Table 2 Data obtained for Uncoated carbide insert for Inconel 718

\begin{tabular}{|c|c|c|c|c|c|c|c|}
\hline EXP NO & $\begin{array}{c}\text { Speed } \\
(\mathrm{m} / \mathrm{min})\end{array}$ & $\begin{array}{c}\text { Feed } \\
(\mathrm{mm} / \mathrm{rev})\end{array}$ & $\begin{array}{c}\text { DOC } \\
(\mathrm{mm})\end{array}$ & $\begin{array}{l}\text { Hardness } \\
(\mathrm{HRC})\end{array}$ & $\begin{array}{l}\text { Tool Wear } \\
(\mathrm{mm})\end{array}$ & $\begin{array}{l}\text { Surface Roughness } \\
(\mu \mathrm{m})\end{array}$ & $\begin{array}{l}\text { Temperature } \\
\left({ }^{\circ} \mathrm{C}\right)\end{array}$ \\
\hline 1 & 1 & 1 & 1 & 1 & 0.245 & 1.13 & 199 \\
\hline 2 & 1 & 2 & 2 & 2 & 0.185 & 1.06 & 180 \\
\hline 3 & 1 & 3 & 3 & 3 & 0.200 & 1.19 & 180 \\
\hline 4 & 2 & 1 & 2 & 3 & 0.200 & 0.96 & 181 \\
\hline 5 & 2 & 2 & 3 & 1 & 0.200 & 1.06 & 197 \\
\hline 6 & 2 & 3 & 1 & 2 & 0.220 & 0.94 & 180 \\
\hline 7 & 3 & 1 & 3 & 2 & 0.210 & 1.03 & 330 \\
\hline 8 & 3 & 2 & 1 & 3 & 0.175 & 0.85 & 0.98 \\
\hline
\end{tabular}


Table 3 Data obtained for Coated carbide insert for Inconel 718

\begin{tabular}{|c|c|c|c|c|c|c|c|}
\hline EXP NO & $\begin{array}{c}\text { Speed } \\
(\mathrm{m} / \mathrm{min})\end{array}$ & $\begin{array}{c}\text { Feed } \\
(\mathrm{mm} / \mathrm{rev})\end{array}$ & $\begin{array}{c}\text { DOC } \\
(\mathrm{mm})\end{array}$ & $\begin{array}{c}\text { Hardness } \\
(\mathrm{HRC})\end{array}$ & $\begin{array}{l}\text { Tool Wear } \\
(\mathrm{mm})\end{array}$ & $\begin{array}{l}\text { Surface Roughness } \\
(\mu \mathrm{m})\end{array}$ & $\begin{array}{l}\text { Temperature } \\
\left({ }^{\circ} \mathrm{C}\right)\end{array}$ \\
\hline 1 & 1 & 1 & 1 & 1 & 0.190 & 1.150 & 315 \\
\hline 2 & 1 & 2 & 2 & 2 & 0.175 & 0.960 & 1.702 \\
\hline 3 & 1 & 3 & 3 & 3 & 0.160 & 0.924 & 410 \\
\hline 4 & 2 & 1 & 2 & 3 & 0.190 & 0.972 & 240 \\
\hline 5 & 2 & 2 & 3 & 1 & 0.145 & 0.760 & 190 \\
\hline 6 & 2 & 3 & 1 & 2 & 0.140 & 1.264 & 190 \\
\hline 7 & 3 & 1 & 3 & 2 & 0.190 & 0.842 & 400 \\
\hline 8 & 3 & 2 & 1 & 3 & 0.170 & 1.865 & \\
\hline 9 & 3 & 3 & 2 & 1 & 0.140 & & 240 \\
\hline
\end{tabular}

Table 4 Data obtained for Ceramic insert for Inconel 718

\begin{tabular}{|c|c|c|c|c|c|c|c|}
\hline EXP NO & $\begin{array}{l}\text { Speed } \\
(\mathrm{m} / \mathrm{min})\end{array}$ & $\begin{array}{l}\text { Feed } \\
(\mathrm{mm} / \mathrm{rev})\end{array}$ & $\begin{array}{l}\text { DOC } \\
(\mathrm{mm})\end{array}$ & $\begin{array}{l}\text { Hardness } \\
(\mathrm{HRC})\end{array}$ & $\begin{array}{l}\text { Tool Wear } \\
(\mathrm{mm})\end{array}$ & $\begin{array}{l}\text { Surface Roughness } \\
(\mu \mathrm{m})\end{array}$ & $\begin{array}{l}\text { Temperature } \\
\left({ }^{\circ} \mathrm{C}\right)\end{array}$ \\
\hline 1 & 1 & 1 & 1 & 1 & 0.129 & 2.2818 & 200 \\
\hline 2 & 1 & 2 & 2 & 2 & 0.149 & 2.3402 & 201 \\
\hline 3 & 1 & 3 & 3 & 3 & 0.140 & 2.2884 & 202 \\
\hline 4 & 2 & 1 & 2 & 3 & 0.190 & 2.3438 & 203 \\
\hline 5 & 2 & 2 & 3 & 1 & 0.118 & 2.0687 & 194 \\
\hline 6 & 2 & 3 & 1 & 2 & 0.116 & 2.0440 & 194 \\
\hline 7 & 3 & 1 & 3 & 2 & 0.193 & 2.3662 & 203 \\
\hline 8 & 3 & 2 & 1 & 3 & 0.122 & 2.1324 & 210 \\
\hline 9 & 3 & 3 & 2 & 1 & 0.111 & 5.4356 & 232 \\
\hline
\end{tabular}

\subsection{Evaluation of Various features for Inconel 718}

Various features were calculated by using Lab VIEW software and MATLAB for each signal collected by AE sensor. These features and corresponding outputs (tool wear, surface roughness and temperature) trained with neural network by considering the parameters got high accuracy of $98 \%$. Based upon the training the above performance curves were plotted. After obtaining satisfactory relation between features and outputs in neural network training, the simulated results were optimized based on Grey relation analysis. Using Anova the optimized values are verified for consistency.

\subsection{Artificial Neural Network for AE}

The obtained features were trained in neural network by considering the parameters shown in Fig.2,3,4 \& 5 and got maximum accuracy of $98 \%$. 


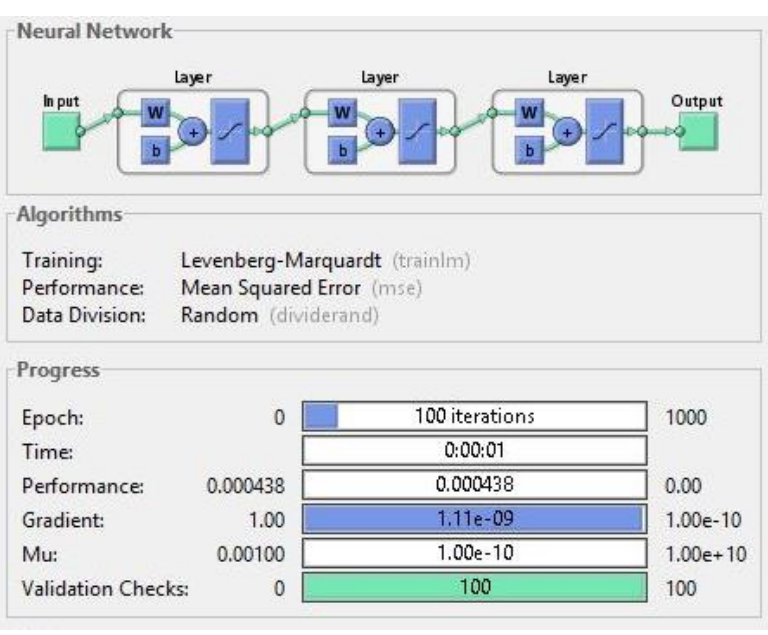

Figure 2 Neural Network for AE Signals

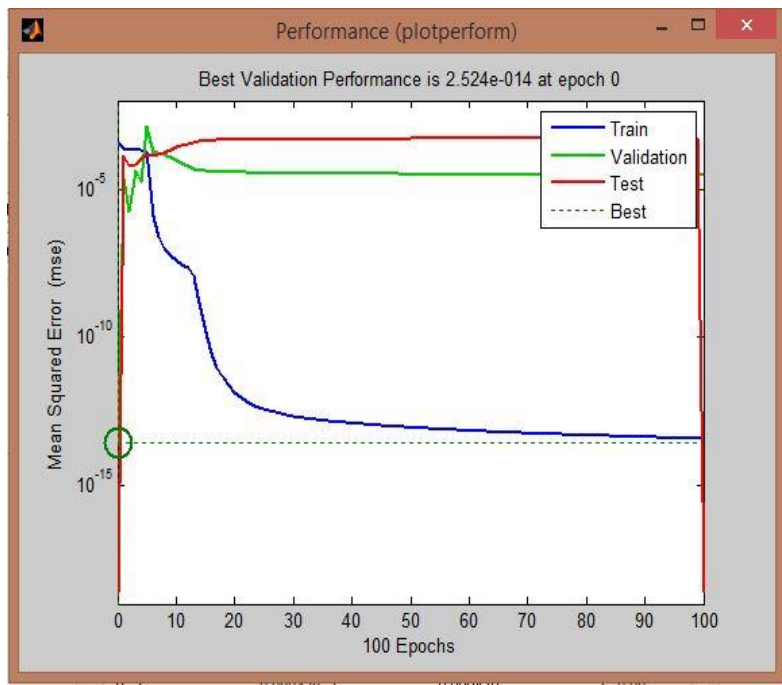

Figure 4 Performance Graph for AE signals

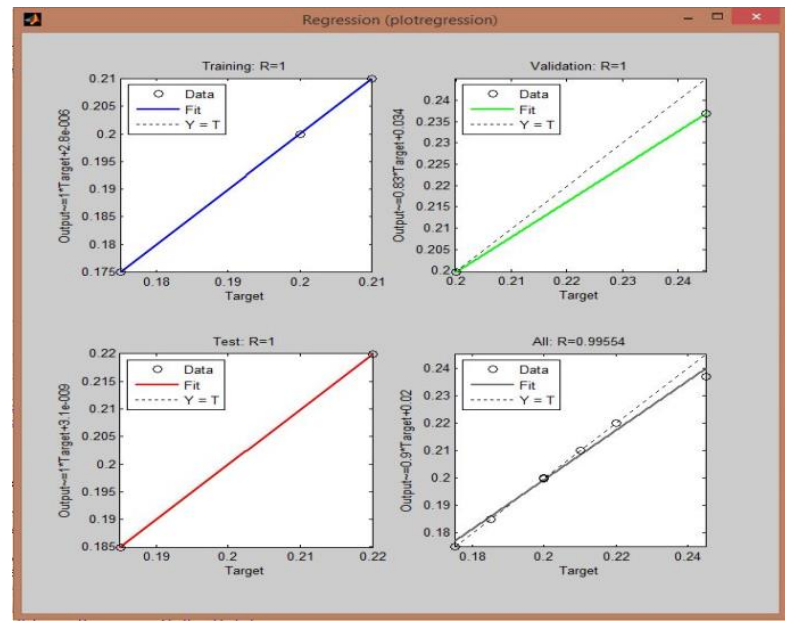

Figure 3 Regression Graph for AE signals

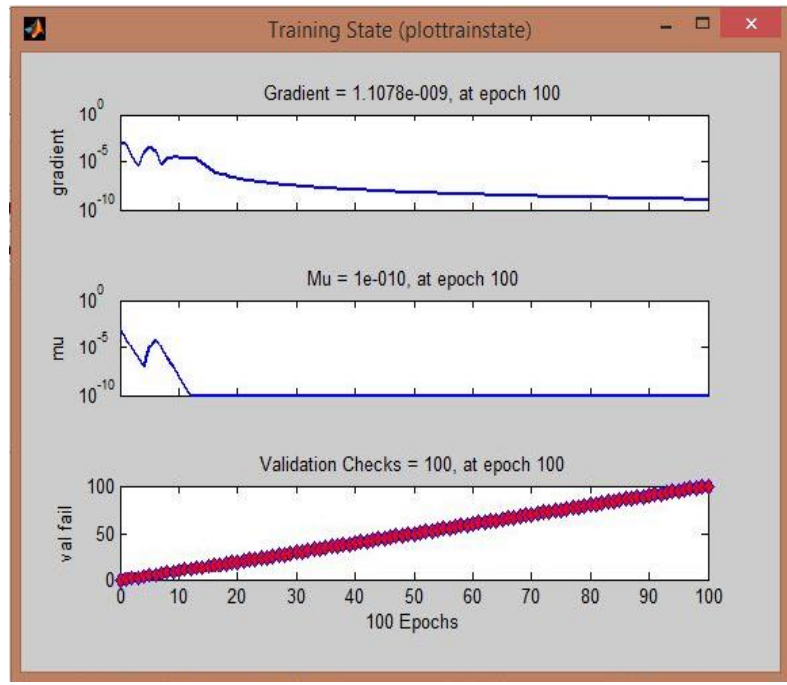

Figure 5 Training State Graph for AE

\subsection{Grey relation Analysis for AE}

If the value of grey grade is greater, the combination of corresponding factors is said to be near to the optimal. The average grey grade of each factor was attained by taking the average grey grade for the appropriate factor at the required level. The optimum level for each factor was reached on the basis of the ' greater is better' characteristic. The pattern of the grey grade of the experimental runs was graphically described in Fig.6. Thus, the dominating sequence for Uncoated carbide was Skewness (SKW), TIME, Standard Deviation (SD), Root mean square (RMS), Variance (VAR), MEAN, Frequency (FRE), Absolute Deviation (AD), PEAK, Kurtosis (KURT), Crest Factor (CF). Similarly, the dominating sequence for Coated carbide was KURT, SKW, FRE, TIME, PEAK, RMS, VAR, MEAN, CF, AD, SD. And the dominating sequence for Ceramic insert was RMS, AD, CF, SD, MEAN, KURT, FRE, VAR, SKW, PEAK, TIME. 


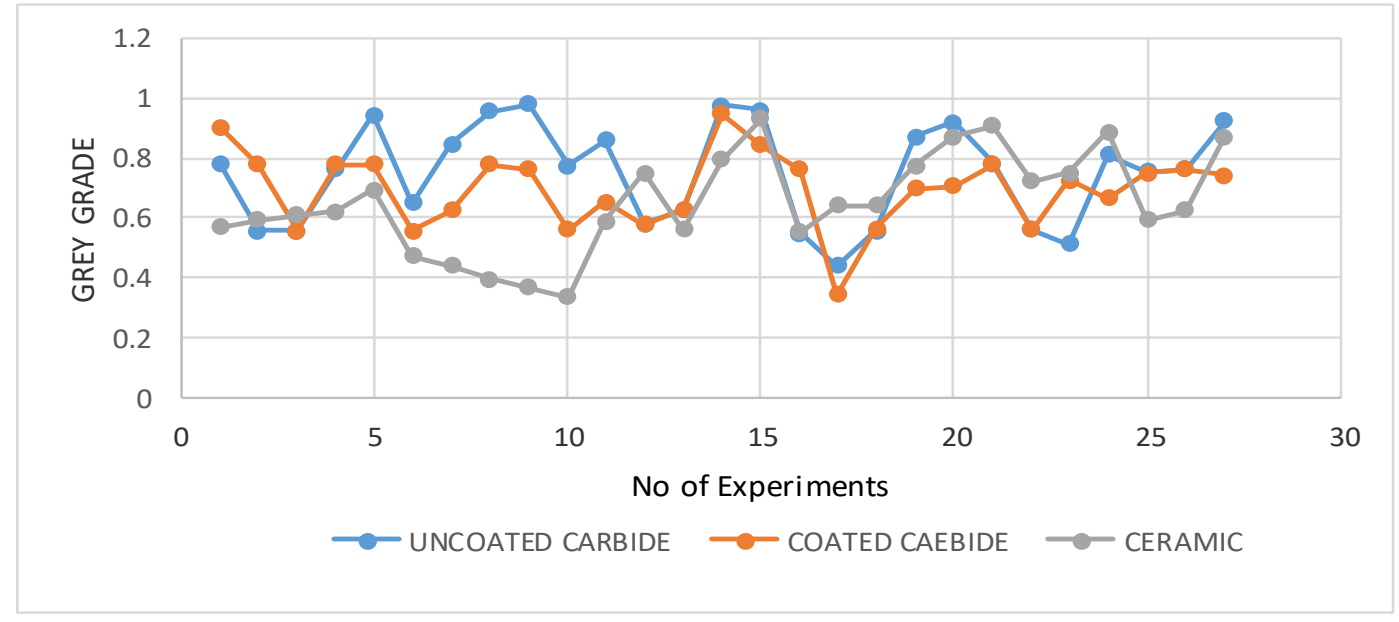

Figure 6 GRA grades of experimental trails for AE

\subsection{Anova Analysis for AE}

According to this analysis and percentage contribution, a factor with a high percentage contribution, there is a greater effect on the performance of tool wear. Thus, the domina sequence again supported by ANOVA is same as GRA results. From ANOVA sequence of percentage contribution of each feature was shown in Fig.7.

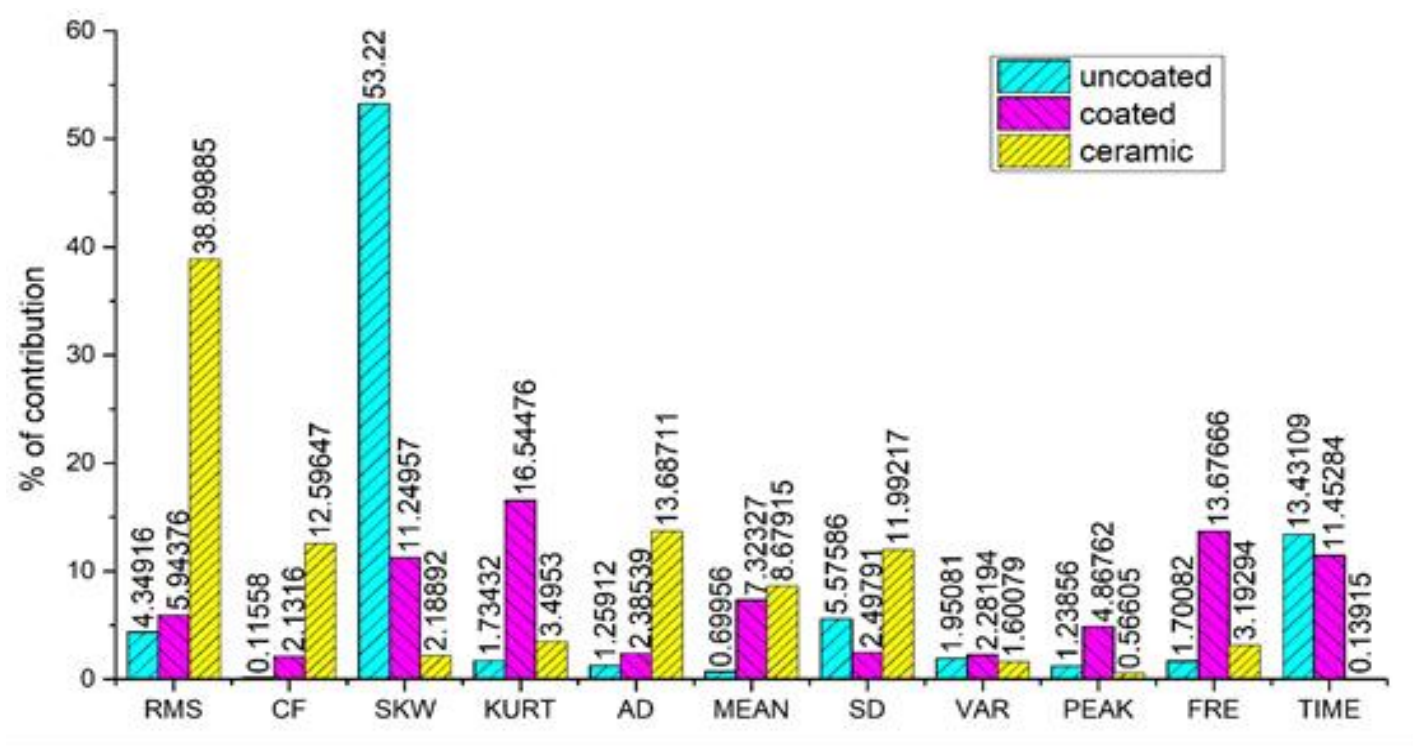

\subsection{Mathematical model for tool wear based on Acoustic Emission technique}

All together there are eleven independent features and one dependent feature. The dependent feature is tool wear and the all other are independent in experimental. To find out the dominant features amongst all the eleven independent features we have carried out the Akaike's Information Criteria (AIC).

The first five dominant features in our findings are Kurtosis, Frequency, Variance, Mean, RMS based on these five features neglecting the other six features which are contributing less to the tool wear we have calculated a mathematical model as a ready use for any experimentor. Based on these five dominant features the mathematical model is

$$
\begin{array}{r}
Y=a_{0}+a_{1} X_{1}+a_{2} X_{2}+a_{3} X_{3}+a_{4} X_{4}+a_{5} X_{5} \\
T W=a_{0}+a_{1}(K U R T)+a_{2}(F R E)+a_{3}(V A R)+a_{4}(M E A N)+a_{5}(R M S)
\end{array}
$$

Where

$\mathrm{a}_{0}$ is the intercept and $\mathrm{a}_{1}, \mathrm{a}_{2}, \mathrm{a}_{3}, \mathrm{a}_{4}$, are the statistical constants which are calculated by method of least squares. 
Table 5 AIC values from Acoustic Emission

\begin{tabular}{|l|c|l|l|l|}
\hline & Df & Sum of Sq & RSS & AIC \\
\hline <none> & & 0.0033496 & & -228.86 \\
\hline - avgkurt & 1 & 0.00032939 & 0.0036790 & -228.33 \\
\hline - avgfre & 1 & 0.00037996 & 0.0037296 & -227.96 \\
\hline+ avgvar & 1 & 0.00010803 & 0.0032416 & -227.74 \\
\hline+ avgmean & 1 & 0.00005939 & 0.0032902 & -227.34 \\
\hline+ avgrms & 1 & 0.00004137 & 0.0033082 & -227.19 \\
\hline+ avgskw & 1 & 0.00003977 & 0.0033098 & -227.18 \\
\hline+ avgad & 1 & 0.0000854 & 0.0033411 & -226.93 \\
\hline - avgpeak & 1 & 0.00064756 & 0.0039972 & -226.09 \\
\hline - avgcf & 1 & 0.00066502 & 0.0040146 & -225.97 \\
\hline - avgtime & 1 & 0.00113409 & 0.0044837 & -222.99 \\
\hline - avgsd & 1 & 0.00214775 & 0.0054973 & -217.48 \\
\hline
\end{tabular}

Using R- Programming the least squares method formula is calculated as $\operatorname{lm}($ formula $=$ avgtw $\sim$ avgkurt + avgfree + avgvar + avgmean + avgrms) i.e

$\mathrm{TW}=-4.273 \mathrm{e}-17+1.734 \mathrm{e}-33$ avgkurt $+1.000 \mathrm{e}+00$ avgfree $+1.916 \mathrm{e}-19$ avgvar $+7.471 \mathrm{e}-19$ avgm ean $-5.065 \mathrm{e}-1$ 9avgrms

By plotting the points the residual versus leverages is given as

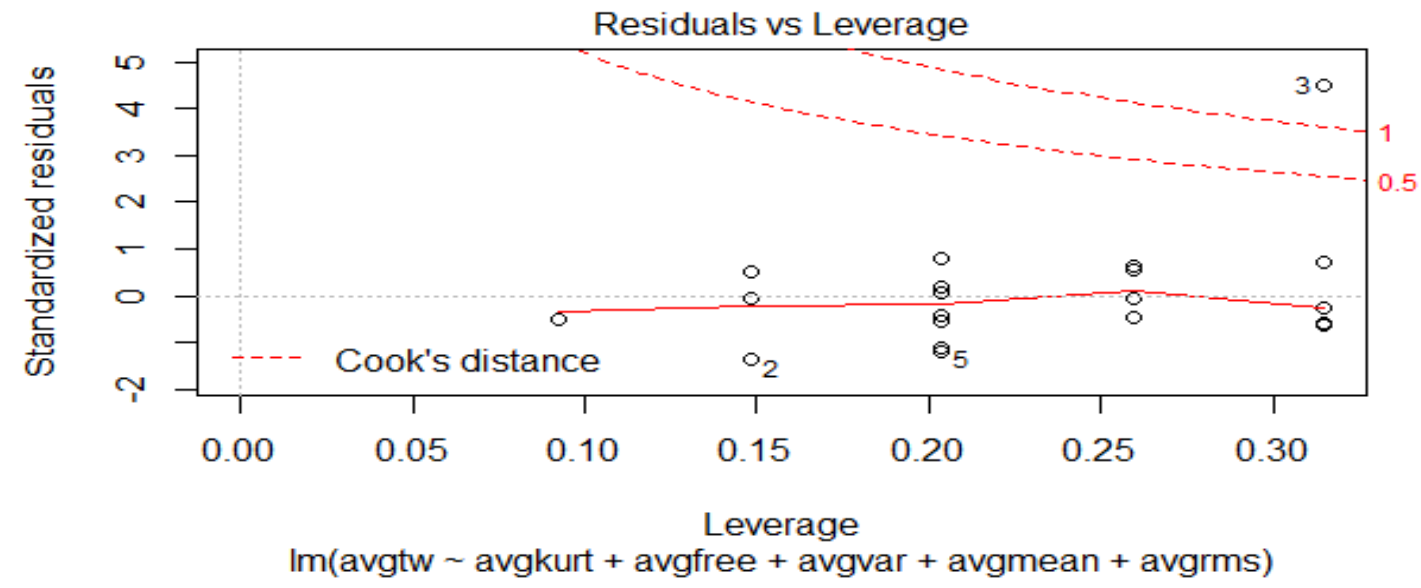

Figure 8 Variation of residuals and leverage of features from AE signals

\section{Conclusions}

AE signals were collected from the LabVIEW software and the features were measured from the acquired signals using the MAT LAB software. By using neural network to train the features for the relationship between tool wear, surface roughness, temperature and features and has been found to be approximately 98 percent accurate. The output parameters were determined by simulation of neural network where all features were considered as input data from L27 orthogonal array. The simulated data was evaluated using the Gray Relational Approach and the Gray Grade obtained, which is used to assess the dominant function of the tool condition monitoring. The dominant features of the AE signal series of Uncoated, Coated carbide and Ceramic insert were obtained using Gray relational analysis. Although ANOVA analysis was supported out for the neural network simulated statistics and Gray codes, it was observed that same Features rating sequence was obtained for the AE 
signal. Dominant features are varied for tool wear of three tools in AE. The Mathematical model developed for tool wear based on dominant features obtained by Akaike information criteria for AE technique. Based on mathematical model for features of AE it was observed KURTOSIS, FREQUENCY, VARIANCE, MEAN, RMS are considerable dominant features.

\section{References}

1. Battula, B., Anusha, V., Praveen, N., Shankar, G., \& Latchoumi, T. P. (2020). Prediction of Vehicle Safety System Using Internet of Things. Journal of Green Engineering, 10(4), 1786-1798.

2. Barat, V. A., et al. (2019). "Acoustic emission model of fatigue crack in low-carbon steel." International Journal of Mechanical and Production Engineering Research and Development 9.6 433-442

3. Bartarya, G.; Choudhury, S.K. (2012) State of the hard turning International Journal of Machine Tools \& Manufacture, 53(1), 1-14.

4. Binsaeid, Sultan, Shihab Asfour, Sohyung Cho, and Arzu Onar. (2009). "Machine ensemble approach for simultaneous detection of transient and gradual abnormalities in end milling using multisensor fusion." Journal of Materials Processing Technology 209(10) 4728-4738.

5. Blum, T., and I. Inasaki. "A study on acoustic emission from the orthogonal cutting process." (1990): 203-211.

6. Byrne, G., David Dornfeld, Ichiro Inasaki, G. Ketteler, Wilfried König, and Roberto Teti. (1995). "Tool condition monitoring (TCM) - the status of research and industrial application." CIRP annals 44(2) 541567.

7. DALPIAZ, Giorgio, and M. Remondi. (1988). "Use of acoustic emission for cutting process monitoring in turning." 1-26.

8. Davim, J.P. Machining of Hard Materials; (2011). Springer: London, pp. 1-32.

9. Garikapati, P., Balamurugan, K., Latchoumi, T. P., \& Malkapuram, R. (2020). A Cluster-Profile Comparative Study on Machining AlSi $7 / 63 \%$ of SiC Hybrid Composite Using Agglomerative Hierarchical Clustering and K-Means. Silicon, 1-12.

10. Eftekharnejad, Babak, M. R. Carrasco, B. Charnley, and David Mba. (2011) "The application of spectral kurtosis on acoustic emission and vibrations from a defective bearing. " Mechanical Systems and Signal Processing 25(1), 266-284.

11. Emel, E., and E. Kannatey-Asibu Jr. (1988). "Tool failure monitoring in turning by pattern recognition analysis of AE signals." 137-145.

12. Jemielniak, K., and O. Otman. (1998) "Tool failure detection based on analysis of acoustic emission signals." Journal of Materials Processing Technology 76(1-3) 192-197.

13. Kannatey-Asibu Jr, E., and D. A. Dornfeld. (1982), "A study of tool wear using statistical analysis of metal-cutting acoustic emission." Wear 76(2), 247-261.

14. Koshy .P, R.C. Dewes, D.K. Aspinwall, (2002). High speed end milling of hardened AISI D2 tool steel(58 HRC), Journal of Materials Processing Technology 127266-273.

15. Latchoumi, T. P., \& Parthiban, L. (2018). Advanced Overlap Community Detection by Associative Rule Mining and Multi-View Ant Clustering. International Journal of Engineering and Technology, 7, 21-29.

16. Latchoumi, T. P., Loganathan, J., Parthiban, L., \& Janakiraman, S. (2016, August). OFS method for selecting active features using clustering techniques. In Proceedings of the International Conference on Informatics and Analytics (pp. 1-4).

17. Latchoumi, T. P., \& Parthiban, L. (2016). Secure Data Storage in Cloud Environment using MAS. Indian Journal of Science and Technology, 9, 24-29.

18. LI Dan, J. (1990). Mathew tool wear and failure monitoring techniques for turning a review, Int. J.Machine Tools Manufact. 30(4), 579-598. 1990. 0890-6955/9053.00 +.00 Printed in Great Britain Int. J.Machine Tools Manufact.

19. Moriwaki, T., and M. Tobito. (1990). "A new approach to automatic detection of life of coated tool based on acoustic emission measurement." 212-218.

20. MOFLEH, AHMED F., AHMED N. SHMROUKH, and NOUBY M. GHAZALY. (Jun 2020). "FAULT DETECTION AND CLASSIFICATION OF SPARK IGNITION ENGINE BASED ON ACOUSTIC SIGNALS AND ARTIFICIAL NEURAL NETWORK. " International Journal of Mechanical and Production Engineering Research and Development (IJMPERD) 10(3), 5571-5578 
21. Narayanan, Siva Bala, Jing Fang, Gary Bernard, and Les Atlas. "Feature representations for monitoring of tool wear." In Proceedings of ICASSP'94. IEEE International Conference on Acoustics, Speech and Signal Processing, 6, VI-137. IEEE, 1994.

22. Ravindra, H. V., Y. G. Srinivasa, and R. Krishnamurthy. (1997). "Acoustic emission for tool condition monitoring in metal cutting." Wear 212(1) 78-84.

23. Shankar, G., Latchoumi, T. P., Chithambarathanu, M., Balayesu, N., \& Shanmugapriya, C. (2020). An Efficient Survey on Energy Conservation System with Video Surveillance. Journal of Xian University of Architecture and Technology, 12(7), 100-106.

24. Sharma, Vishai S., S. K. Sharma, Ajay K. Sharma, and A. Bhardwaj. (2006). "A model for cutting tool wear estimation." Journal for Manufacturing Science and Production 7(1) 35-48.

25. Taur, P. G., and S. A. Sonawane. (Feb 2015), "ANALYSIS OF WEAR RESISTANCE OF TOOL STEEL AFTER DEEP CRYOGENIC TREATMENT." International Journal of Mechanical and Production Engineering Research and Development (IJMPERD) 5(1), 11-24

26. Vasanth, V., Venkatachalapathy, K., Thamarai, L., Parthiban, L., \& Ezhilarasi, T. P. (2017). A survey on cache route schemes to improve QoS in AD-HOC networks. Pakistan Journal of Biotechnology, 14, 265269.

27. Vasanth, A. V., Venkatachalapathy, K., Latchoumi, T. P., Parthiban, L., Sowmia, T., \& OhmPrakash, V. (2018). An Efficient Cache Refreshing Policy to Improve QoS in MANET Through RAMP. In Proceedings of the Second International Conference on Computational Intelligence and Informatics (pp. 369-381). Springer, Singapore.

28. Xiaozhi C, Beizhi L AE (2007). method for tool condition monitoring based on wavelet analysis. Int J Adv Manufacturing Technology 33, 968-976

29. YADAV, G. PRAVEEN KUMAR, M. LAVA KUMAR, and M. MURALI MOHAN. (Apr 2018). "THERMOACOUSTIC REFRIGERATION SYSTEM. " International Journal of Mechanical and Production Engineering Research and Development(IJMPERD) 8, 2, 397-402

30. Zhou, Jun-Hong, Chee Khiang Pang, Zhao-Wei Zhong, and Frank L. Lewis. (2010). "Tool wear monitoring using acoustic emissions by dominant-feature identification." IEEE Transactions on Instrumentation and Measurement 60(2) 547-559.

31. Zhou, Jun-Hong, Chee Khiang Pang, Zhao-Wei Zhong, and Frank L. Lewis. (2010) "Tool wear monitoring using acoustic emissions by dominant-feature identification." IEEE Transactions on Instrumentation and Measurement 60(2) 547-559.

32. Zhu, Kunpeng P., Geok S. Hong, and Yoke S. Wong. (2008) "A comparative study of feature selection for hidden Markov model-based micro-milling tool wear monitoring." Machining Science and Technology 12(3), 348-369. 